\title{
Quantification of Perfluoroalkyl Compounds in Drinking Water Sources of the Western Cape, South Africa
}

\author{
X. Booi, J.B.N. Mudumbi, S.K.O. Ntwampe, E.I. Omodanisi, A.P. Daso, M.S. Sheldon and S. Odisitse
}

\begin{abstract}
We report for the first time the concentrations of perfluoroalkyl compounds in water sources of the Western Cape. Recently, perfluorooctanoate (PFOA) and perfluorooctane sulfonate (PFOS) were detected in sediments from a South African environment, particularly for the largest catchment areas of the Western Cape, South Africa, an area associated with the largest agricultural sector. A liquid chromatography/tandem mass spectrometer (LC/MS/MS) was used to analyze the PFCs. From the results, five different PFCs (i.e. PFHpA, PFDoA, PFNA, PFUA, and PFDeA) were detected in raw water. PFHpA was detected with the highest concentration $(27.13 \mathrm{ng} / \mathrm{L})$ from Steenbras WTP, followed by Faure and Wemmershoek WTPs (24.19 ng/L and $22.671 \mathrm{ng} / \mathrm{L}$, respectively). The average concentrations of other PFCs were as follows: PFDoA - $4.415 \mathrm{ng} / \mathrm{L}, \mathrm{PFNA}-1.880 \mathrm{n} / \mathrm{L}$ and PFDeA $2.744 \mathrm{ng} / \mathrm{L}$, all for Faure WTP; and PFUA - $4.488 \mathrm{ng} / \mathrm{L}$ for Wemmershoek WTP. PFOA and PFOS were below the limit of detection (LOD).
\end{abstract}

Manuscript received September 10, 2019. This work was supported by the Cape Peninsula University of Technology (CPUT) under Grant RK16.

$\mathrm{X}$. Booi was with the Bioresource Engineering Research Group (BioERG), Department of Biotechnology, Faculty of Applied Sciences, Cape Peninsula University of Technology, Keizersgracht and Tennant Street, Zonnebloem, P.O. Box 652, Cape Town, 8000, South Africa.

J.B.N. Mudumbi is with the Bioresource Engineering Research Group (BioERG), Faculty of Applied Sciences, Department of Biotechnology, Cape Peninsula University of Technology, Keizersgracht and Tennant Street, Zonnebloem, P.O. Box 652, Cape Town, 8000, South Africa.

S.K.O. Ntwampe is the founder of Bioresource Engineering Research Group (BioERG), Faculty of Engineering and the Built Environment, Department of Chemical Engineering, Cape Peninsula University of Technology, PO Box 1906, Bellville, 7535, South Africa.

E.I. Omodanisi is with the Bioresource Engineering Research Group (BioERG), Department of Biotechnology, Faculty of Applied Sciences, Cape Peninsula University of Technology, Keizersgracht and Tennant Street, Zonnebloem, P.O. Box 652, Cape Town, 8000, South Africa.

A.P. Daso is with the Department of Environmental, Water and Earth Sciences, Faculty of Science, Tshwane University of Technology, Pretoria 0083, South Africa.

M.S. Sheldona is with the Faculty of Engineering and the Built Environment, Department of Chemical Engineering, Cape Peninsula University of Technology, PO Box 1906, Bellville, 7535, South Africa.

S. Odisitse is with the Faculty of Science, Department of Chemistry and Forensic Sciences, Botswana International University of Sciences and Technology, P/bag x16, Palapye, Botswana, BW
Keywords- Perfluoroheptanoic acid (PFHpA), Perfluorooctanoate (PFOA), Perfluorooctane sulfonate (PFOS), Perfluoroalkyl compounds, Drinking water source.

\section{INTRODUCTION}

Water plays a major role in our lives and our water resources must be managed in a manner that ensures its sustainability. South Africa is a country that regularly faces water shortages, especially in the townships. A study by Smith [1] predicted that with the current rate of water consumption, the existing system of water supply is likely to run-out within a few decades. Additionally, the quality of water, whether intended for drinking or irrigation, is of significant importance to human health worldwide, in both developed and developing countries. The state of water quality can have a major impact on human health when it is not properly managed, as poor quality water can result in outbreaks of water-borne diseases. In addition to the pathogenic micro-organisms that affect the state of our water, perfluoroalkyl compounds (PFCs) have been proven to be one of the chemicals that intoxicate water sources and have a detrimental effect on human health, living organisms and plants.

(PFCs) are persistent, bio-accumulative and toxic fluorine-based chemicals [2]. They do not occur naturally, they are used in man-made fluorinated compounds in consumer and industrial applications [3]. In other words, they are synthetic organic compounds and have been manufactured worldwide since the 1950s. They are present in the environment because they are used in various applications such as textiles, clothes, carpets, cosmetics and fire-fighting foams [4]. The common route of exposure to humans is through the consumption of PFC-contaminated water and foods [5[, [6]. As water usage and consumption is the basis of everyday human activity and as a result of the resistance of the PFOA and PFOS to hydrolysis, biological breakdown and metabolism by vertebrates due to the strength of the carbon-fluorine bond; these fluorine-based organic compounds can be easily consumed, thus bio-accumulate in the body [7].

Several studies have been done worldwide with results showing widespread presence of PFCs in the environment: for example, they have been detected in environmental and tap water [4], [5], [8]; in human semen [3]; and in human sera [2], [9]-12]. Furthermore, high levels of PFC contamination have been detected in various media globally, such as in drinking 
water treatment plants, landfills and living organisms [11] and in food [13]. However, in South Africa, the study of PFC contamination in drinking water sources has never been reported, except that perfluoroalkyl compounds were detected for the first time in maternal serum and cord blood of pregnant women at $1.6 \mathrm{ng} / \mathrm{mL}$ for perfluorooctane sulfonate (PFOS) and $1.3 \mathrm{ng} / \mathrm{mL}$ for perfluorooctanoic acid (PFOA) [9], and river water and suspended solids [14].

Based on the results obtained from various PFC contamination studies, some countries determined a need to develop regulatory limits as guidelines for acceptable PFC levels in drinking water for human consumption based on human health effects [15]. There is limited existing national legislation that defines specific limit values for all PFCs, particularly in South Africa. In 2009, the USEPA issued drinking water provisional health advisory, but only for PFOA and PFOS, with a maximum limit of $400 \mathrm{ng} / \mathrm{L}$ and $200 \mathrm{ng} / \mathrm{L}$ for both compounds, respectively [16]. However, in South Africa, PFC regulation is non-existent and therefore devoid of regulatory guidelines. The SABS (SANS 241), which governs drinking water quality, issued drinking water specifications for the different parameters as found in SANS 241: 2005. Microbial, physical, organoleptic, and chemical safety requirements are all specified in the guidelines with no mention of any of the perfluorinated chemicals (PFCs). Prior to the 2010 FIFA World Cup, the Department of Water Affairs and Forestry (DWAF) conducted audits on the drinking water quality management evaluations to comply with current Blue Drop Certification requirements. During the audit, common microbiological and chemical analyses were performed, but again with no mention of PFC contamination [17]. In addition, the new SANS 241:2011 still does not have guidelines for any PFCs. The question that arises from this information is that if PFCs have been proven toxic and detrimental to human health, what must be done in South Africa to closely monitor PFC contamination and prevalence in order to implement treatment strategies thus preserve the quality of our already scarce water resource.

As a result of this alarming void of regulations which governs the maximum PFC limits in South Africa, the greatest concern is that the South African population may be unknowingly exposed to high levels of PFCs via drinking water. As these compounds are water soluble, conventional water treatment systems and processes may not eliminate these compounds completely [7]. From the reviewed literature, more than $70 \%$ of the published research primarily reports on the two abundant PFCs, namely PFOA and PFOS, with much less attention given to other perfluoroalkyl compounds. Furthermore, although other PFCs have been studied and detected in water sources by some researchers, the USEPA only issued drinking water guideline limits for PFOA and PFOS, with no mention of the other PFCs. However, these other PFCs have the same properties as PFOA and PFOS and therefore it is logical to hypothesize that they have the same detrimental health effects to humans as PFOA and PFOS. This study, then, focused on the detection of several other PFCs in drinking water sources of the Western Cape, including PFOS and PFOA.

This study reports on the prevalence and concentrations of perfluoroalkyl compounds in raw water from the drinking water treatment plants (DWTPs) of the Western Cape, South Africa, with an extensive focus on treatment works with a theoretical treatment capacity exceeding $100 \mathrm{~mL} /$ day.

\section{MATERIALS AND METHODS}

\section{A. Sample collection}

Samples used in this study were collected from the following drinking water treatment plants (DWTPs): Atlantis, Blackheath, Brooklands, Faure, Steenbras, Voelvlei, and Wemmershoek. Several batches $(n=4)$ were collected from the DWTP to ascertain consistency in PFC prevalence for a period of three months (October to December 2012) - when access to the DWTPs was given without restrictions). All samples were collected in duplicate in 2L Polypropylene bottles with screw caps. Sample bottles were then filled in such a manner that no air bubbles were entrapped. Sample blanks were prepared in duplicate with organic-free water (water filtered through activated carbon and HLB cartridges) prior to shipping the sample bottles to the sampling site and were shipped along with the sample bottles from the sampling site back to the laboratory.

\section{B. Sample preparation and extraction}

The sample bottles, extraction flasks and volumetric flasks including ancillary materials were rinsed with analytical grade methanol, which was passed through a Hydrophilic-lipophilic balance (HLB) cartridge to remove any traces of PFCs. After the rinse, materials were air dried and then placed in an oven at $105^{\circ} \mathrm{C}$ for 1 hour and then allowed to cool. Samples and the blanks were stored as a set in the refrigerator at $\pm 4^{\circ} \mathrm{C}$ for a period of 48 hours to 1 week (maximum) prior to analysis.

Prior to sample extraction, each cartridge (Supel-Select HLB SPE cartridges - $500 \mathrm{mg}$ solid phase, $12 \mathrm{~mL}$ tubes) was rinsed with $15 \mathrm{~mL}$ of analytical grade methanol followed by $18 \mathrm{~mL}$ of Milli-Q water, without allowing the water to drop below the top edge of the adsorbent packing material. The solid phase was kept wet for optimal extraction and also to avoid cracking of the packing material. At this stage, it was important to ensure that the packing material did not go dry at any of the conditioning steps. If the cartridge did go dry during the conditioning phase, the conditioning was redone. The sample extraction was performed according to a modified EPA method 537-31: i.e. about $500 \mathrm{~mL}$ each of spiked Milli-Q water and collected water (source or raw) samples were transferred into methanol rinsed $1 \mathrm{~L}$ polypropylene beakers. During extraction, the vacuum was adjusted so that the approximate flow rate ranged between 8.93 to $12.5 \mathrm{~mL} / \mathrm{min}$. It was important to ensure that the cartridge did not go dry before the entire sample has passed through the cartridge during the extraction. After the $500 \mathrm{~mL}$ sample had passed through the cartridge, the beaker was rinsed with $10 \mathrm{~mL}$ of Milli-Q water and the resultant residual water was transferred into the cartridge. Thereafter, air was drawn through the cartridges for 10 minutes at high vacuum (10 to $15 \mathrm{in} \mathrm{Hg}$ ) to ensure that the entire sample has been removed from the 
cartridge. This process was repeated for each of the duplicate samples. Subsequently the cartridges were eluted with $8 \mathrm{~mL}$ of analytical grade methanol, after which a gentle stream of high purity nitrogen gas was used to reduce the volume of eluents to $\sim 1 \mathrm{~mL}$. The final extract was then transferred into a properly labelled sample vial and stored in the refrigerator until analysis (LC/MS/MS).

\section{Sample analysis and calibration chromatographs}

The PFC analysis was performed in accordance with EPA method 537-31 using the LC/MS/MS. Operating parameters are shown in Table 1, while Figure 1 illustrates the chromatographs for the seven PFCs detected with their retention times. The mean of two injected samples was used for all the samples.

\section{Method modification, validation and quality control for} perfluoroalkyl compounds

Water sample volume used for the extraction process was increased from $250 \mathrm{~mL}$ to $500 \mathrm{~mL}$. Each extraction cycle was duplicated to ascertain the concentration and consistency in the extraction process for PFCs for each sample. For quality control, blank samples of Milli-Q (de-ionized water) were used with each extraction batch to confirm that potential background contaminants were not interfering with the identification or quantitation of method analytes. Analytes (PFDoA and PFUA) in the blank samples were only detected in one batch only of the three batches that were analysed for PFCs and the concentrations were negligible. Calibration standards were analysed at the beginning of each analysis batch. The final analyte concentration was determined as follows: (i) The concentrations of the analytes detected in the blank samples were subtracted from the concentration of the respective analytes detected in the samples. (ii) The final concentration was calculated as follows:

Final analyte concenfration $=\frac{\text { Concentration detected } x \text { Sample volume injected }}{\text { Sample volume extracted }}$
TABLE I: SUMMARY OF LC/MS/MS OPERATIONAL PARAMETERS USED

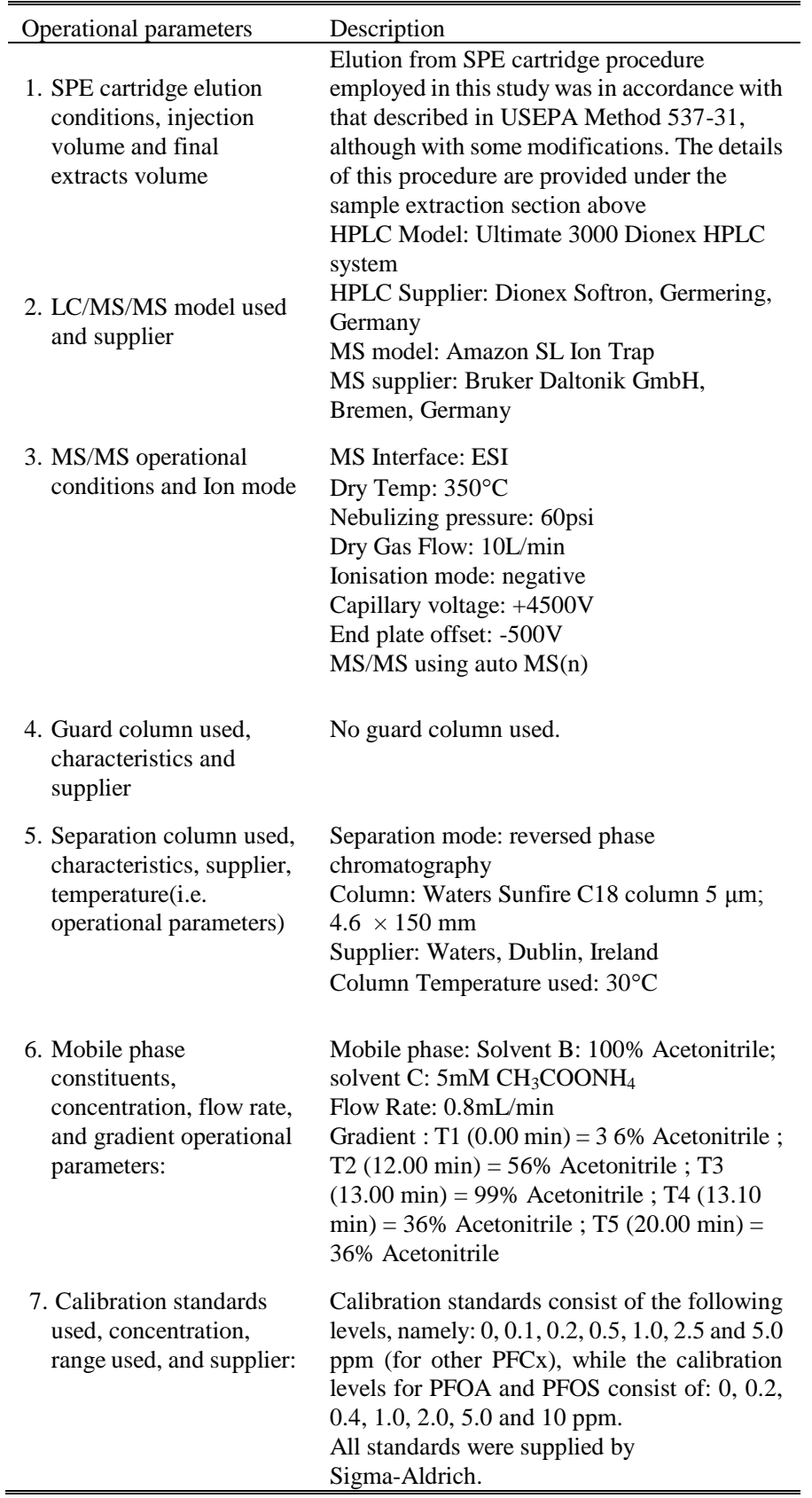




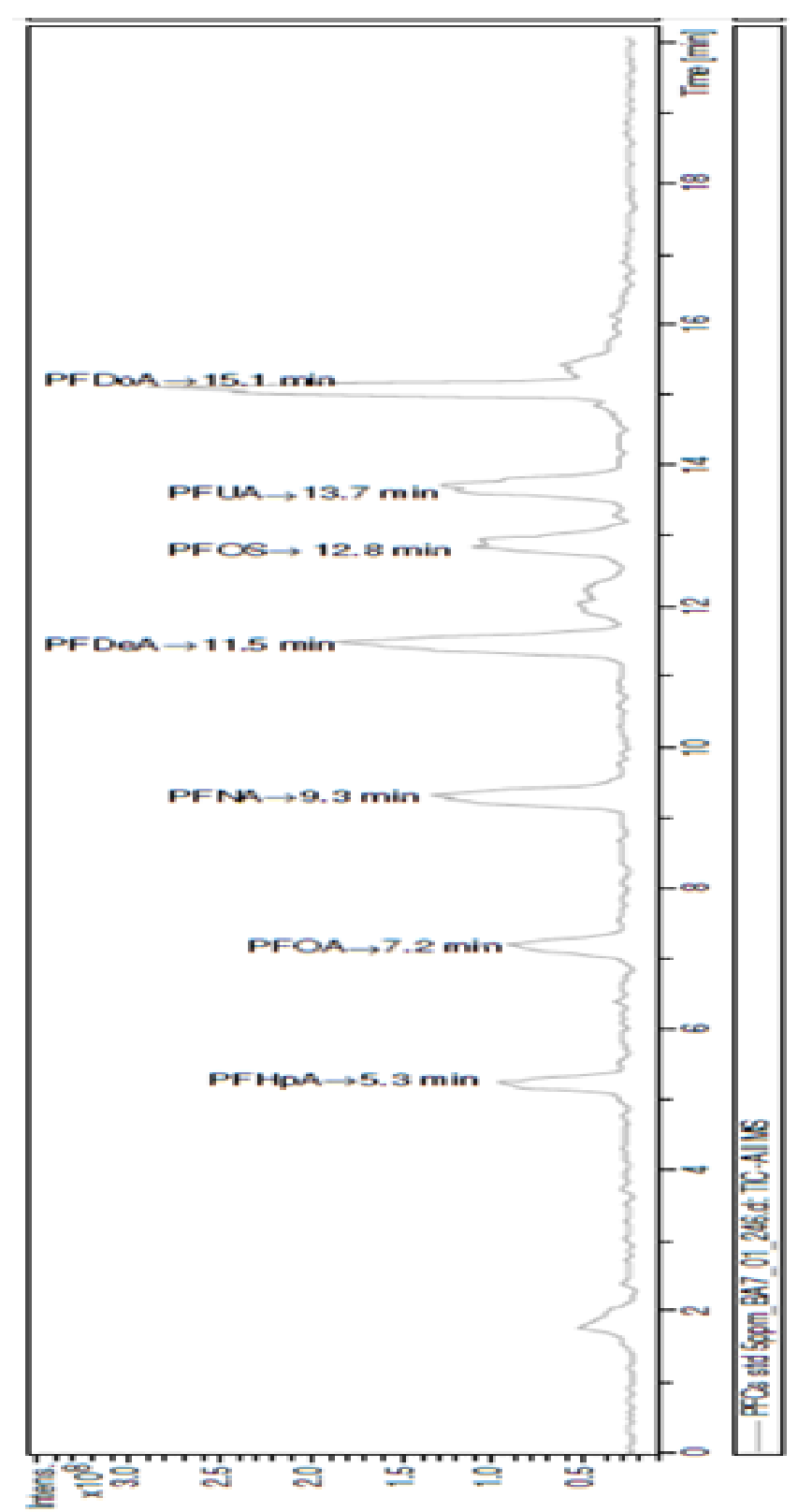

Fig 1. LC/MS/MS chromatograms for Perfluoroheptanoic acid (PFHpA, RT = $5.3 \mathrm{~min}, \mathrm{~m} / \mathrm{z}$ 362.7), Perfluorooctanoic acid (PFOA, $\mathrm{RT}=7.2 \mathrm{~min}, \mathrm{~m} / \mathrm{z}$ 412.7), Perfluorononanoic acid (PFNA, RT $=9.3$ $\mathrm{min}, \mathrm{m} / \mathrm{z}$ 462.8), Perfluorodecanoic acid (PFDeA, RT $=11.5 \mathrm{~min}, \mathrm{~m} / \mathrm{z}$ 512.8), Perfluorooctane sulfonate (PFOS, RT $=12.8 \mathrm{~min}, \mathrm{~m} / \mathrm{z} 498.8$ ), Perfluoroundecanoic acid (PFUA, RT $=13.7 \mathrm{~min}, \mathrm{~m} / \mathrm{z} 562.9$ ), and Perfluorododecanoic acid (PFDoA, RT = $15.1 \mathrm{~min}, \mathrm{~m} / \mathrm{z}$ 612.9).

E. Method modification, validation and quality control for perfluoroalkyl compounds

Water sample volume used for the extraction process was increased from $250 \mathrm{~mL}$ to $500 \mathrm{~mL}$. Each extraction cycle was duplicated to ascertain the concentration and consistency in the extraction process for PFCs for each sample. For quality control, blank samples of Milli-Q (de-ionized water) were used with each extraction batch to confirm that potential background contaminants were not interfering with the identification or quantitation of method analytes. Analytes (PFDoA and PFUA) in the blank samples were only detected in one batch only of the three batches that were analysed for PFCs and the concentrations were negligible. Calibration standards were analysed at the beginning of each analysis batch. The final analyte concentration was determined as follows: (i) The concentrations of the analytes detected in the blank samples were subtracted from the concentration of the respective analytes detected in the samples. (ii) The final concentration was calculated as follows:

Final analyte concentration $=\frac{\text { Concentration detected } x \text { Sample volume injected }}{\text { Sample volume extracted }}$

\section{RESULTS AND DISCUSSION}

\section{A. Perfluoroalkyl compounds (PFCs) in raw water sources of the Western Cape, South Africa}

The average PFC concentrations detected in this study are presented in Table 2. Important to note: (1) The PFC results reported here are from analysis performed in raw water from seven DWTPs, and tap water was not analysed; and (2) the study of health effects of these PFCs and the background study on the areas were beyond the scope of this study. For the purpose of this study, the limit of detection (LOD) was set at 0.2 $\operatorname{ppm}(200 \mu \mathrm{g} / \mathrm{L})$ for PFOA and PFOS and at $0.1 \mathrm{ppm}(100 \mu \mathrm{g} / \mathrm{L})$ for other PFCs, with the reasoning that any PFCs detected above these limits would indicate a widespread public health concern. The foundation for this is based on the literature reviewed. From the studies performed on PFCs and as seen in more than $70 \%$ of the literature reviewed during this study, most researchers focused on PFOA and PFOS, their presence in water sources and their detrimental health effects to humans and living organisms with substantially less attention given to the other PFCs. 


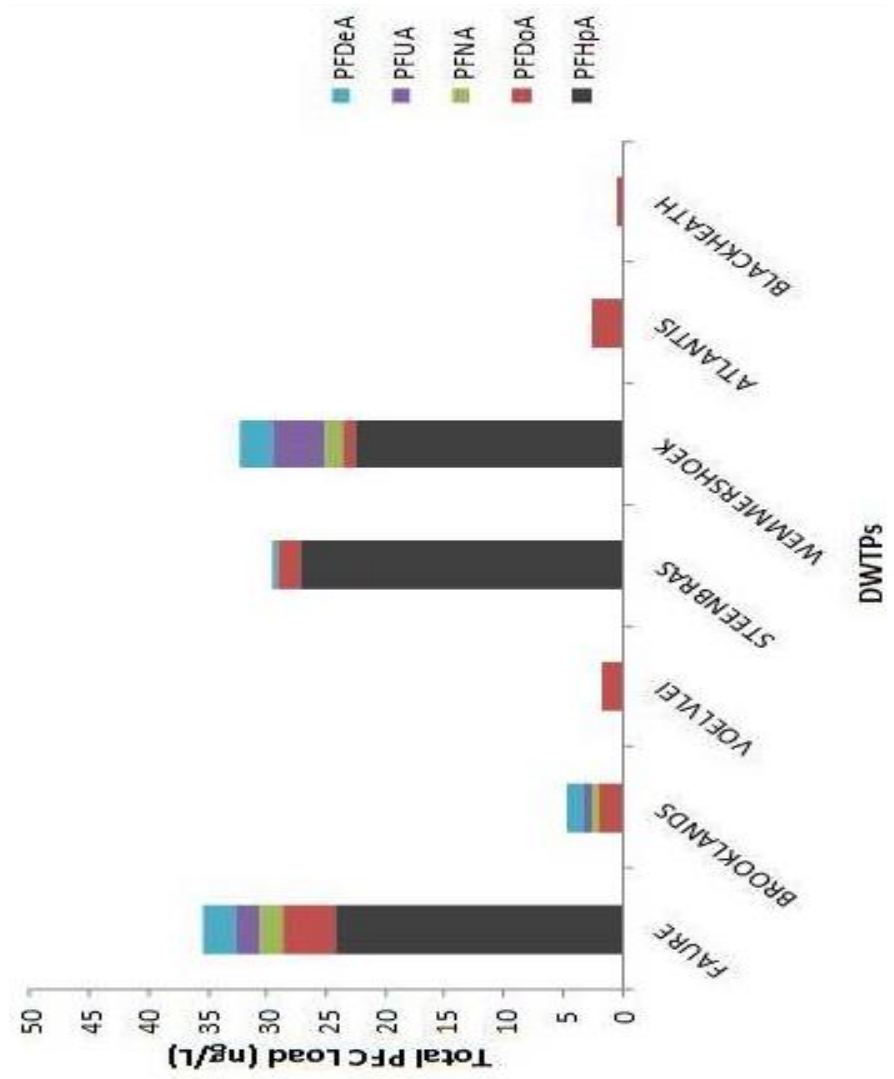

Fig. 2. Concentrations of perfluoroalkyl compounds detected in raw water sources of the Western Cape, South Africa

From the results obtained in this study (Table 2 and Figure 2), five different PFCs (i.e. PFHpA, PFDoA, PFNA, PFUA and PFDeA ) were detected in raw water above the limit of detection of $0.1 \mathrm{mg} / \mathrm{L}(100 \mu \mathrm{g} / \mathrm{L})$. Perfluoroheptanoic acid (PFHpA) was the highly detected PFC at maximum average concentration of $27.13 \mathrm{ng} / \mathrm{L}$ for Steenbras raw water source (i.e. Steenbras lower dam), followed by $24.19 \mathrm{ng} / \mathrm{L}$ for Faure raw water source (i.e. Riviersonderend and Palmiet rivers) and $22.67 \mathrm{ng} / \mathrm{L}$ for Wemmershoek raw water source (i.e. Wemmershoek dam). However, PFHpA was detected below LOD in four DWTPs raw water sources. PFDoA (perfluorododecanoic acid) was detected in all the samples at concentrations ranging from $0.384 \mathrm{ng} / \mathrm{L}$ for Blackheath to $4.415 \mathrm{ng} / \mathrm{L}$ for Faure raw water sources, PFNA (perfluorononanoic acid) and PFDeA (perfluorodecanoic acid) were detected in four DWTPs raw water sources, followed by PFUA (perfluoroundecanoic acid), which was detected in three DWTPs raw water sources; all concentrations were below 5 ng/L (for PFNA, PFDeA and PFUA). The highly researched and reported Perfluorooctanoic acid (PFOA) and Perfluorooctane sulfonate (PFOS) were not detected in any of the evaluated raw water sources because their concentrations were below the LOD of $200 \mu \mathrm{g} / \mathrm{L}$. Overall, for Faure and Wemmershoek raw water sources, all five PFCs were detected above the LOD.
TABLE II: CONCENTRATIONS OF PERFLUOROALKYL COMPOUNDS DETECTED ABOVE THE LOD $(100 \mu \mathrm{G} / \mathrm{L})$ IN WATER SOURCES OF THE WESTERN CAPE. PERFLUOROHEPTANOIC ACID (PFHPA); PERFLUORODODECANOIC ACID (PFDOA)

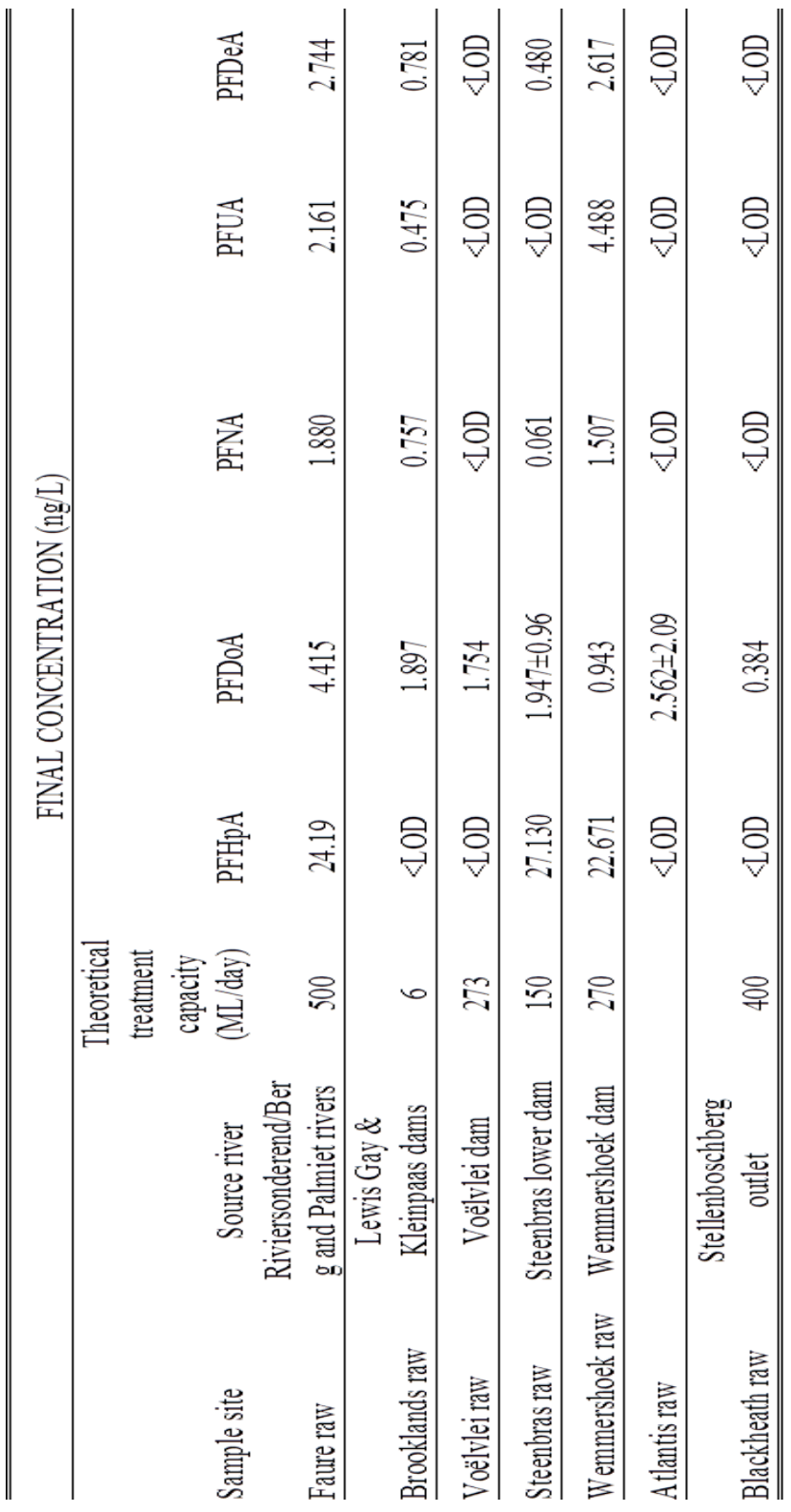

\section{CONCLUSION}

The main objective of this study was to detect and identify perfluoroalkyl compounds that are present in water sources of the Western Cape, South Africa. From the results obtained, five PFCs were detected in raw water sources in seven DWTPs of the Western Cape, South Africa above the limit of detection of $0.1 \mathrm{mg} / \mathrm{L}$. These compounds are reported for the first time from water sources in the Western Cape and this results highlights the predominance of most PFCs in water sources, such that future studies should not only focus on PFOA and PFOS, particularly in South Africa. Once more, the WHO and the SABS must consider establishing guideline values for these PFCs for continuous monitoring. 


\section{ACKNOWLEDGMENT}

The authors are grateful to the Cape Peninsula University of Technology (CPUT) for its financial support, Dr. S. Odisitse, Ms. L Muedi, Mrs. Z. Mthembu, Dr. T. Kudanga and Dr. P. Daso (Tshwane University of Technology) for their valuable assistance.

\section{REFERENCES}

[1] L. Smith, "The urban political ecology of water in Cape Town," Urban Forum, vol 2, pp. 204-224, April 2001. https://doi.org/10.1007/s12132-001-0016-4

[2] D. Skutlarek, M. Exner and H. Farber, "Perfluorinated surfactants in surface and drinking waters" Environmental Science Pollution Research, vol. 13, no. 5, pp. 299-307, September 2006. https://doi.org/10.1065/espr2006.07.326

[3] U.N. Joensen, R. Bossi, H. Leffers, A.A. Jensen, N.E Skakkebæk, and N. Jørgensen, "Do perfluoroalkyl compounds impair human semen quality?" Environmental health perspectives, vol. 117, no. 6, pp. 923-927, June 2009. https://doi.org/10.1289/ehp.0800517

[4] Y.H. Jin, W. Liu, I. Sato, S.F. Nakayama, K. Sasaki, N. Saito and S. Tsuda, "PFOS and PFOA in environmental and tap water in China," Chemosphere, vol. 77, no. 5, pp. 605-611, October 2009. https://doi.org/10.1016/j.chemosphere.2009.08.058

[5] I. Ericson, R. Martí-Cid, M. Nadal, B. Van Bavel, G. Lindström and J.L. Domingo, "Human exposure to perfluorinated chemicals through the diet: intake of perfluorinated compounds in foods from the Catalan (Spain) market," Journal of agricultural and food chemistry, vol. 56, no. 5, pp. 1787-1794, February 2008. https://doi.org/10.1021/jf0732408

[6] M. Strynar, S. Nakayama, L. Helfant and A. Lindstrom, "Determination of perfluorinated compounds in surface soils," Reproductive Toxicology, vol. 3, no. 27, p. 425, 2009. https://doi.org/10.1016/j.reprotox.2008.11.079

[7] S. Takagi, F. Adachi, K. Miyano, Y. Koizumi, H. Tanaka, M. Mimura, I. Watanabe, S. Tanabe and K. Kannan, "Perfluorooctanesulfonate and perfluorooctanoate in raw and treated tap water from Osaka, Japan," Chemosphere, vol. 72, no. 10, pp. 1409-1412, August 2008. https://doi.org/10.1016/j.chemosphere.2008.05.034

[8] G.B. Post, J.B. Louis, K.R. Cooper, B.J. Boros-Russo and R.L. Lippincott, "Occurrence and potential significance of perfluorooctanoic acid (PFOA) detected in New Jersey public drinking water systems," Environmental science \& technology, vol. 43, no. 12, pp. 4547-4554, May 2009.

https://doi.org/10.1021/es900301s

[9] L. Hanssen, H. Röllin, J.Ø. Odland, M.K. Moe and T.M. Sandanger, "Perfluorinated compounds in maternal serum and cord blood from selected areas of South Africa: results of a pilot study," Journal of environmental monitoring, vol. 12, no. 6, pp. 1355-1361, April 2010. https://doi.org/10.1039/b924420d

[10] J. Hölzer,, O. Midasch,, K. Rauchfuss,, M. Kraft,, R. Reupert,, J. Angerer,, P. Kleeschulte,, N. Marschall and M. Wilhelm, "Biomonitoring of perfluorinated compounds in children and adults exposed to perfluorooctanoate-contaminated drinking water," Environmental health perspectives, vol. 116, no. 5, pp. 651-657, May 2008. https://doi.org/10.1289/ehp.11064

[11] F. Oliaei, D. Kriens, R. Weber and A. Watson, "PFOS and PFC releases and associated pollution from a PFC production plant in Minnesota (USA)," Environmental Science and Pollution Research, vol. 20, no. 4, pp. 1977-1992, April 2013. https://doi.org/10.1007/s11356-012-1275-4

[12] K. Steenland, C. Jin, J. MacNeil, C. Lally, A. Ducatman, V. Vieira and T. Fletcher, "Predictors of PFOA levels in a community surrounding a chemical plant," Environmental health perspectives, vol. 117, no. 7, pp. 1083-1088, July 2009.

https://doi.org/10.1289/ehp.0800294

[13] D.B. Clarke, V.A. Bailey, A. Routledge, A.S. Lloyd, S. Hird, D.N. Mortimer and M. Gem, "Dietary intake estimate for perfluorooctanesulphonic acid (PFOS) and other perfluorocompounds (PFCs) in UK retail foods following determination using standard addition LC-MS/MS," Food Additives and Contaminants, vol. 27, no. 4, pp. 530-545, March 2010.

https://doi.org/10.1080/19440040903476590

[14] J.B.N. Mudumbi, S.K.O. Ntwampe, F.M. Muganza and J.O. Okonkwo, "Perfluorooctanoate and perfluorooctane sulfonate in South African river water," Water Science and Technology, vol. 69, no. 1, pp. 185-194, January 2013. https://doi.org/10.2166/wst.2013.566

[15] P.C. Rumsby, C.L McLaughlin, and T. Hall, "Perfluorooctane sulphonate and perfluorooctanoic acid in drinking and environmental waters," Philosophical Transactions of the Royal Society A: Mathematical, Physical and Engineering Sciences, vol. 367, no. 1904, pp. 4119-4136, October 2009.

https://doi.org/10.1098/rsta.2009.0109

[16] United States Environmental Protection Agency. (April 2009). Sampling Investigation Trip Report North Georgia Public Water Suppliers Perfluorinated Compounds Study North Georgia including Dalton, Calhoun, Rome and Floyd County. Available: https://archive.epa.gov/pesticides/region4/water/documents/web/pdf/doc _a_sampling_investigation.pdf.

[17] Blue Drop Certification, (March 2010). Drinking Water Quality Regulation. Available: http://www.capewatersolutions.co.za/2010/03/15/blue-drop-certification /.

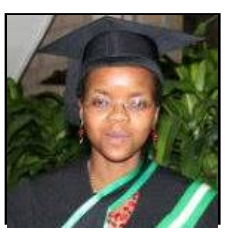

X. Booi was born in Cape Town on 30 December 1984 and grew up in the Eastern Cape, Keiskammahoek at Rabula Location. She attended Emmangweni Primary School and later attended St Matthews High School in Keiskammahoek, where she matriculated with distinction in 2001. In 2002 she enrolled at Cape Peninsula University of Technology (then known as the Cape Technikon) for a National Diploma in Chemical Engineering, which she was awarded (cum laude) in 2004. In 2005 she enrolled for BTech in Chemical Engineering, which she also passed (cum laude). She enrolled for a Magister Technologiae degree in 2010 under the direct supervision of Prof. Karabo Ntwampe and co-supervision of Prof. Marshall Sheldon and Dr. Sebusi Odisitse. Her research was based on the analysis of Perfluorinated compounds and Trihalomethanes in drinking water sources of the Western Cape. She is currently working at Eskom, Koeberg Nuclear Power Station, in the Western Cape. 